\title{
Risk factors for impaired maternal bonding when infants are 3 months old: a longitudinal population based study from Japan
}

Mami Nakano ${ }^{1}$, Subina Upadhyaya ${ }^{2}$, Roshan Chudal ${ }^{2}$, Norbert Skokauskas ${ }^{3}$, Terhi Luntamo ${ }^{2}$, Andre Sourander ${ }^{2}$ and Hitoshi Kaneko ${ }^{4 *}$ (D)

\begin{abstract}
Background: Impaired maternal bonding has been associated with antenatal and postnatal factors, especially postpartum depression. Only a few population-based, longitudinal studies have examined the association between maternal depression and bonding in outside western countries. In addition, little is known about the association between psychosocial factors during pregnancy and impaired maternal bonding. The aim of this study was to investigate risk factors associated with impaired maternal bonding 3 months after delivery using Japanese population-based, longitudinal study from pregnancy period to 3 months after delivery.

Methods: This study was performed at the public health care center in Hekinan city, Aichi prefecture, Japan. Mothers who participated the infant's health check-up 3 months after delivery from July 2013 to Jun 2015 completed the Postpartum Bonding Questionnaire (PBQ) and the Edinburgh Postnatal Depression Scale (EPDS) 1 month after delivery. Information was also provided from home visit at 1 month after delivery, birth registration form, and pregnancy notification form. The study included 1060 mothers with a mean age of 29.90 years, who had given birth at a mean of 38.95 weeks.

Results: Bivariate and multivariate logistic regression analyses were conducted to identify the association between antenatal and postnatal factors and impaired maternal bonding. The main findings were that maternal negative feelings about pregnancy $(\mathrm{OR}=2.16,95 \% \mathrm{Cl}=1.02-4.56)$ and postpartum depression at 1 month after delivery $(\mathrm{OR}=7.85,95 \% \mathrm{Cl}=3.44-17.90)$ were associated with higher levels of impaired maternal bonding 1 months after delivery. Mothers who had delivered their first child had increased odds of a moderate level of impaired maternal bonding 3 months after delivery $(\mathrm{OR}=1.85,95 \% \mathrm{Cl}=1.22-2.81)$.
\end{abstract}

Conclusions: The findings emphasize the importance of identifying mothers with depression and those with maternal negative feelings towards pregnancy to assess possible impaired maternal bonding.

Keywords: Bonding, Postpartum depression, Population-based longitudinal study, Maternal negative feelings towards pregnancy, Primipara

\footnotetext{
* Correspondence: kaneko@cc.nagoya-u.ac.jp

${ }^{4}$ Psychological Support and Research Center for Human Development,

Nagoya University, Furo-cho, Chikusa-ku, Nagoya, Japan

Full list of author information is available at the end of the article
}

(c) The Author(s). 2019 Open Access This article is distributed under the terms of the Creative Commons Attribution 4.0 International License (http://creativecommons.org/licenses/by/4.0/), which permits unrestricted use, distribution, and reproduction in any medium, provided you give appropriate credit to the original author(s) and the source, provide a link to the Creative Commons license, and indicate if changes were made. The Creative Commons Public Domain Dedication waiver (http://creativecommons.org/publicdomain/zero/1.0/) applies to the data made available in this article, unless otherwise stated. 


\section{Background}

The quality of the emotional tie between a mother and her baby, which was first described as bonding more than 40 years ago [1], is crucial for the infant's survival and psychosocial development. Maternal bonding can start during the antenatal period [2] and is associated with postnatal bonding $[3,4]$. Impaired maternal bonding can result in a higher risk of abusive parenting [5], poor mother-infant interaction [6] and children's behavioral problems [7]. Studies have reported that the prevalence of impaired maternal bonding has ranged from 6 to $41 \%$ in clinical samples of the mother-infant dyads [8-13] to about $1 \%$ in the general population $[9,13,14]$. However, most of the previous research has been conducted in Western countries.

Impaired maternal bonding has been associated with a number of maternal risk factors, including both antenatal $[3,15]$ and postpartum depression $[16,17]$. These results have been found in Western countries [3, 16, 17] and Asian countries [13], including Japan [18-22]. Impaired maternal bonding has also been associated with maternal anxiety [18], maternal insecure attachment [23], primiparity [24], poor family support [25], intimate partner violence [26], unintended pregnancy [27] and unplanned Cesarean section [28]. Furthermore, it has been associated with factors such as preterm birth [29], giving birth to a girl [13], and the infant's sleep problems [7].

To our knowledge, most previous longitudinal studies investigating the risk factors for impaired maternal bonding did not collect data from the first trimester of pregnancy [13-19]. Although one study collected data from the first trimester [3], this information was collected for a proportion of participants retrospectively, which may pose a memory bias. As maternal bonding already starts to emerge early in pregnancy, it is of major importance to reliably identify early risk factors in order to be able to prevent the development of impaired maternal bonding. Additionally, in the majority of studies, maternal bonding has been measured during the first 2 months after giving birth $[15,18]$. As it has been suggested that maternal bonding could be formed until 3 months after delivery [30], it is important to extend the assessment of bonding until then.

The present study addressed above highlighted knowledge gap by aiming to investigate the prenatal and postnatal risk factors associated with impaired maternal bonding 3 months after delivery. We hypothesized that postnatal depression symptoms and prenatal risk factors would be associated with impaired maternal bonding at this time point.

\section{Method}

\section{Participants}

This study was performed from July 2013 to June 2015 at the public health care centre in Hekinan city, Aichi prefecture, Japan. Hekinan city had a population of about 70, 000. The original cohort included 1163 mothers who participated the infant's health check-up 3 months after delivery. Of note, $8.86 \%(n=103)$ of mothers were excluded due to having twins $(0.60 \%)$, not being Japanese $(4.68 \%)$ and not completing the Postpartum Bonding Questionnaire (PBQ) [31, 32] (3.58\%) 3 months after giving birth, resulting in total of 1060 mothers in the study.

The mean maternal age was 29.90 years (Standard Deviation (SD) 5.07, range 16-44 years) with the mean gestational age of 38.95 weeks (SD 1.37, range 33-41 weeks). Less than half of the participants $(n=425$, 41.67\%) were first-time mothers and just over half of the babies were male $(n=550,52.78 \%)$.

\section{Procedure}

This was a longitudinal, population-based study and the procedure was incorporated into the routine work carried out by the maternal and child health care service in Hekinan city, Aichi prefecture, Japan. In Japan, expecting mothers submit their pregnancy notification form to the public health care centre during the first trimester. After delivery, they have to submit the birth registration form to the municipal office within 14 days and this is automatically transferred to the public health care centre. The health condition of mother and infant 1 month after delivery is assessed by staff at public health care centre through home visit. Three to 4 months after delivery, the mothers visit the public health care centre for a checkup.

Information for the study was collected at four time points: the first trimester of pregnancy by pregnancy notification form, until 2 weeks after delivery by birth registration form, 1 month after delivery by home visiting, and 3 months after delivery by infant's check-up.

\section{Measurements \\ Edinburgh postnatal depression scale (EPDS)}

We used Edinburgh Postnatal Depression Scale (EPDS) $[33,34]$ to assess whether the mothers had postnatal depression one month after delivery. The EPDS is a self-rating scale and includes 10 items scored from 0 (no, not at all) to 3 (yes, all the time). Higher EPDS scores represent greater postnatal depression. The scale has a high internal consistency (Cronbach's alpha 0.87) and good construct validity [33]. The Japanese version of the EPDS had good validity, and recommended a cut-off score of $\geq 9$ to identify postpartum depression [34]. The sensitivity and specificity of the Japanese version of the EPDS have been reported to be 0.82 and 0.95 , respectively [35]. In this study, 67 (6.45\%) of the 1039 mothers who were assessed by the EPDS 1 months after delivery were identified as having postpartum depression. 
Table 1 Measurements across antenatal and postnatal period

\begin{tabular}{|c|c|c|c|}
\hline \multicolumn{2}{|l|}{ Antenatal } & \multicolumn{2}{|l|}{ Postnatal } \\
\hline $\begin{array}{l}\text { 1. First trimester of pregnancy } \\
\text { (Pregnancy notification form) }\end{array}$ & $\begin{array}{l}\text { 2. Within two weeks after delivery } \\
\text { (Birth registration form) }\end{array}$ & $\begin{array}{l}\text { 3. One month after delivery } \\
\text { (Home visiting) }\end{array}$ & $\begin{array}{l}\text { 4. Three months after delivery (Infant's } \\
\text { check-up) }\end{array}$ \\
\hline 1-1. Mother's age & 2-1. Infant's sex & 3-1. Depression (EPDS) & 4-1. The type of birth \\
\hline 1-2. Parity & 2-2. Birth-weight & & 4-2. Feeding style \\
\hline $\begin{array}{l}\text { 1-3. Maternal feelings toward } \\
\text { pregnancy }\end{array}$ & & & 4-3. Maternal health after delivery \\
\hline 1-4. Maternal stress symptoms & & & $\begin{array}{l}\text { 4-4. Maternal employment status } \\
\text { during the antenatal period }\end{array}$ \\
\hline \multirow{2}{*}{$\begin{array}{l}\text { 1-5. Perceived mental illness before } \\
\text { pregnancy }\end{array}$} & & & 4-5. Gestational age \\
\hline & & & 4-6. Maternal bonding (PBQ) \\
\hline
\end{tabular}

\section{Postpartum bonding questionnaire (PBQ)}

We used the PBQ [31, 32] to assess maternal bonding during the infant health check-up 1 months after delivery. The original version of the PBQ [31] has 25 items with four factors. The Japanese version of the PBQ has 16 items with single factors with high reliability (Cronbach's alpha 0.85) [32]. The back translation was confirmed by the original author of the tool [32]. The number of items used was different at the time of the study, as it was carried out while the Japanese version of the PBQ was still being developed. In this study, we used 15 items from the Japanese PBQ, as these were collected during the whole period of this study. Each item in this self-report scale is scored as 0 (never), 1 (rarely), 2 (sometimes), 3 (quite often), 4 (very often), and 5 (always), and a higher PBQ score means higher level of impaired maternal bonding. As the Japanese version of PBQ does not have validated cut-offs yet, we used data-driven cut-offs. A score above 24 (mean $+2 \mathrm{SD}$ ) was categorized as a high level of impaired maternal bonding, a score of between 17 and 23 (mean +1 SD to mean $+2 \mathrm{SD}$ ) was categorized as a moderate level of impaired maternal bonding and a score under 16 (mean +1 $\mathrm{SD})$ was categorized as a low level of impaired maternal bonding. Consequently, 35 (3.3\%) of mothers were categorized as reporting a high level, $116(10.9 \%)$ of mothers were categorized as reporting a moderate level, and 909 $(85.8 \%)$ of mothers were categorized as reporting a low level of impaired maternal bonding. Although the Japanese version of the PBQ did not show normal distribution in Shapiro-Wilk test, normal distribution is not necessary for setting cut scores (e.g. [36]).

\section{Additional study variables with single questions}

Information from the first trimester of pregnancy Single questions on the pregnancy notification form asked for the mother's age $(\leq 24,25-30,30-34$ or $\geq 35$ years), parity (primipara or multipara), maternal feelings towards pregnancy asking "How did you feel when you found out about this pregnancy?" (delighted or negative feelings i.e., unintended but happy, confused because unintended, or worried), maternal stress symptoms asking "Are you having symptoms such as sleeplessness, irritability, cry easily, lack of motivation etc continuously for 2 weeks during the last year?" (yes or no) and perceived mental illness before pregnancy asking "Have you suffered from a disease in the past or are currently getting treated for one (Disease name: mental illness (depression etc.))" (yes or no).

Information within 2 weeks after delivery The birth registration form included information about the infant's sex (boy or girl) and birth-weight $(\geq 2500 \mathrm{~g}$ or $<2500 \mathrm{~g})$.

Information 3 months after delivery Three months after delivery, during the infant checkup, the mothers were asked about details of the type of birth (vaginal delivery, Cesarean section, assisted delivery, i.e. vacuum extraction or forceps delivery), their feeding style (only breast-feeding, only bottle-feeding or combined breastand bottle-feeding), maternal health after delivery asking "Do you have health problems after delivery?" (problems or no problems), maternal employment status during the antenatal period (employed or unemployed) and gestational age ( $\geq 37$ weeks or $<37$ weeks) (Table 1 ).

\section{Statistical analysis}

Bivariate and multivariate logistic regression analyses were used to identify the associations between the antenatal and postnatal risk factors and impaired maternal bonding. The level of statistical significance used in the bivariate analysis was $p<0.10$ to determine the variables for inclusion in the multivariate logistic regression analysis. The association with impaired maternal bonding to the exposure was reported as odds ratios (ORs) with 95\% confidence intervals (95\% CIs). In the logistic regression analysis, low level of impaired maternal bonding was set up as the reference. Moderate and high level of impaired maternal bonding were then compared to 
Table 2 Frequencies and univariable analysis of the independent variables during the antenatal and postnatal periods

\begin{tabular}{|c|c|c|c|c|c|}
\hline \multirow[t]{3}{*}{ Variable ( $n=$ responses to each question) } & \multicolumn{3}{|c|}{ Level of impaired maternal bonding $n(\%)$} & \multicolumn{2}{|c|}{ Impaired maternal bonding } \\
\hline & & & & \multirow{2}{*}{$\begin{array}{l}\text { Moderate } \\
\text { OR }(95 \% \mathrm{Cl})\end{array}$} & \multirow{2}{*}{$\begin{array}{l}\text { High } \\
\text { OR }(95 \% \mathrm{Cl})\end{array}$} \\
\hline & Low & Moderate & High & & \\
\hline \multicolumn{6}{|l|}{ 1-1. Mother's age (Years) $(n=1040)$} \\
\hline$<24$ & $146(87.95)$ & $17(10.24)$ & $3(1.81)$ & $0.97(0.54-1.76)$ & $0.65(0.18-2.38)$ \\
\hline $25-30$ & $350(86.85)$ & $42(10.42)$ & $11(2.73)$ & Reference & Reference \\
\hline $31-34$ & $222(86.05)$ & $23(8.91)$ & $13(5.04)$ & $0.86(0.51-1.48)$ & $1.86(0.82-4.23)$ \\
\hline$>35$ & $176(82.63)$ & $30(14.08)$ & $7(3.29)$ & $1.42(0.86-2.35)$ & $1.27(0.48-3.32)$ \\
\hline \multicolumn{6}{|l|}{ 1-2. Parity $(n=1020)$} \\
\hline Multipara & $531(89.24)$ & $51(8.57)$ & $13(2.18)$ & Reference & Reference \\
\hline Primipara & $345(81.18)$ & $59(13.88)$ & $21(4.94)$ & $1.78(1.20-2.65)^{*}$ & $2.49(1.23-5.03)^{*}$ \\
\hline \multicolumn{6}{|c|}{ 1-3. Maternal feeling about pregnancy $(n=999)$} \\
\hline Delighted & $624(87.76)$ & $70(9.85)$ & $17(2.39)$ & Reference & Reference \\
\hline Negative feeling (Unintended/Worried) & $234(81.25)$ & $38(13.19)$ & $16(5.56)$ & $1.45(0.95-2.21)+$ & $2.51(1.25-5.05)^{*}$ \\
\hline \multicolumn{6}{|l|}{$1-4$. Maternal stress symptoms $(n=1036)$} \\
\hline No & $851(86.04)$ & $110(11.12)$ & $28(2.81)$ & Reference & Reference \\
\hline Yes & $39(82.98)$ & $2(4.26)$ & $6(12.77)$ & $0.40(0.09-1.67)$ & $4.68(1.83-11.95)^{*}$ \\
\hline \multicolumn{6}{|c|}{ 1-5. Perceived maternal mental illness before pregnancy $(n=1038)$} \\
\hline No & $860(86.26)$ & $108(10.83)$ & $29(2.91)$ & Reference & Reference \\
\hline Yes & $32(78.05)$ & $4(9.76)$ & $5(12.20)$ & $1.00(0.35-2.87)$ & $4.63(1.68-12.76)^{*}$ \\
\hline \multicolumn{6}{|l|}{$2-1$. Infant Sex $(n=1042)$} \\
\hline Boy & $474(86.18)$ & $57(10.36)$ & $19(3.45)$ & Reference & Reference \\
\hline Girl & $422(85.77)$ & $55(11.18)$ & $15(3.05)$ & $1.08(0.73-1.61)$ & $0.89(0.45-1.77)$ \\
\hline \multicolumn{6}{|l|}{ 2-2. Birth weight $(n=1042)$} \\
\hline$\geq 2500 \mathrm{~g}$ & 835 (86.26) & $104(10.74)$ & $29(3.00)$ & Reference & Reference \\
\hline$<2500 \mathrm{~g}$ & $61(82.43)$ & $8(10.81)$ & $5(6.76)$ & $1.05(0.49-2.26)$ & $2.36(0.88-6.31)+$ \\
\hline \multicolumn{6}{|l|}{ 3-1.Postpartum depression $(n=1039)$} \\
\hline No & $848(87.24)$ & $104(10.70)$ & $20(2.06)$ & Reference & Reference \\
\hline Yes & $44(65.67)$ & $8(11.94)$ & $15(22.39)$ & $1.48(0.68-3.24)$ & $14.46(6.93-30.14)^{* * *}$ \\
\hline \multicolumn{6}{|l|}{$4-1$. The type of birth $(n=1053)$} \\
\hline Vaginal delivery & 653 (86.38) & $81(10.71)$ & $22(2.91)$ & Reference & Reference \\
\hline Cesarean section & $187(84.23)$ & $25(11.26)$ & $10(4.50)$ & $1.08(0.67-1.74)$ & $1.59(0.74-3.41)$ \\
\hline Assisted delivery & $62(82.67)$ & $10(13.33)$ & $3(4.00)$ & $1.30(0.64-2.64)$ & $1.44(0.42-4.93)$ \\
\hline \multicolumn{6}{|l|}{ 4-2. Feeding style $(n=1055)$} \\
\hline Only Breast feeding & $587(87.48)$ & $68(10.13)$ & $16(2.38)$ & Reference & Reference \\
\hline Only Bottle feeding & $122(81.88)$ & $21(14.09)$ & $6(4.03)$ & $1.49(0.88-2.52)$ & $1.80(0.69-4.70)$ \\
\hline Breast and bottle feeding & $196(83.40)$ & $26(11.06)$ & $13(5.53)$ & $1.15(0.71-1.85)$ & $2.43(1.15-5.15)^{*}$ \\
\hline \multicolumn{6}{|l|}{ 4-3. Maternal health condition $(n=1056)$} \\
\hline Reported no problems & $858(85.71)$ & $112(11.19)$ & $31(3.10)$ & Reference & Reference \\
\hline Reported problems & $47(85.45)$ & $4(7.27)$ & $4(7.27)$ & $0.65(0.23-1.84)$ & $2.36(0.80-6.95)$ \\
\hline \multicolumn{6}{|l|}{ 4-4. Employment status $(n=1059)$} \\
\hline Employed & $482(86.54)$ & $56(10.05)$ & $19(3.41)$ & Reference & Reference \\
\hline Unemployed & $426(84.86)$ & $60(11.95)$ & $16(3.19)$ & $0.95(0.48-1.88)$ & $1.21(0.82-1.79)$ \\
\hline \multicolumn{6}{|l|}{ 4-5. Gestational age $(n=1059)$} \\
\hline$\geq 37$ weeks & $876(85.97)$ & 111 (10.89) & $32(3.14)$ & Reference & Reference \\
\hline
\end{tabular}


Table 2 Frequencies and univariable analysis of the independent variables during the antenatal and postnatal periods (Continued)

\begin{tabular}{|c|c|c|c|c|c|}
\hline \multirow[t]{3}{*}{ Variable ( $n=$ responses to each question) } & \multicolumn{3}{|c|}{ Level of impaired maternal bonding $n(\%)$} & \multicolumn{2}{|c|}{ Impaired maternal bonding } \\
\hline & & & & \multirow{2}{*}{$\begin{array}{l}\text { Moderate } \\
\text { OR }(95 \% \mathrm{Cl})\end{array}$} & \multirow{2}{*}{$\begin{array}{l}\text { High } \\
\text { OR }(95 \% \mathrm{Cl})\end{array}$} \\
\hline & Low & Moderate & High & & \\
\hline$<37$ weeks & $32(80.00)$ & $5(12.50)$ & $3(7.50)$ & $1.23(0.47-3.23)$ & $2.57(0.75-8.82)$ \\
\hline
\end{tabular}

$* * *<0.0001, * *<0.001,{ }^{*}<0.05,+<0.10$

NA Not applicable

low level of impaired maternal bonding. The variables that were shown to be significant with impaired maternal bonding in the bivariate analysis (Table 2) were selected for the multivariate analysis (Table 3). Since post-partum depression is strongly associated with maternal bonding, we conducted separate multivariate analyses in two models. The first model included all other antenatal and postnatal variables without post-partum depression. The second model included all variables including post-partum depression. Although infant's sex was not significantly associated with impaired maternal bonding in bivariate analysis, we included it in the multivariate analysis, because it is an important demographic variable and has been reported as an important risk factor for impaired maternal bonding especially in Asian culture [13]. The level of statistical significance was $p<$

Table 3 Multivariate analysis with significant risk factors for impaired maternal bonding in univariable analysis, without adjusted depression and adjusted with depression

\begin{tabular}{|c|c|c|c|c|}
\hline \multirow[t]{3}{*}{ Variable } & \multirow{3}{*}{$\begin{array}{l}\text { Multivariate analysis1) } \\
\text { without adjusted depression } \\
\text { Moderate } \\
\text { OR }(95 \% \mathrm{Cl})\end{array}$} & \multicolumn{3}{|c|}{$\begin{array}{l}\text { Multivariate analysis1) } \\
\text { adjusted with depression }\end{array}$} \\
\hline & & High & Moderate & High \\
\hline & & OR $(95 \% \mathrm{Cl})$ & OR $(95 \% \mathrm{Cl})$ & OR $(95 \% \mathrm{Cl})$ \\
\hline \multicolumn{5}{|l|}{ 1-2. Parity } \\
\hline Multipara & Reference & Reference & Reference & Reference \\
\hline Primipara & $1.83(1.22-2.76)^{*}$ & $2.47(1.19-5.13)^{*}$ & $1.85(1.22-2.81)^{*}$ & $1.97(0.92-4.23)$ \\
\hline \multicolumn{5}{|l|}{ 1-3. Maternal feeling about pregnancy } \\
\hline Delighted & Reference & Reference & Reference & Reference \\
\hline Negative feeling (Unintended/worried) & $1.53(0.99-2.35)$ & $2.40(1.17-4.96)^{*}$ & $1.46(0.94-2.28)$ & $2.16(1.02-4.56)^{*}$ \\
\hline \multicolumn{5}{|l|}{ 1-4. Maternal stress symptoms } \\
\hline No & Reference & Reference & Reference & Reference \\
\hline Yes & $0.36(0.08-1.56)$ & $2.58(0.86-7.73)$ & $0.22(0.03-1.65)$ & $1.85(0.57-5.98)$ \\
\hline \multicolumn{5}{|c|}{ 1-5. Perceived maternal mental illness pregnancy before } \\
\hline No & Reference & Reference & Reference & Reference \\
\hline Yes & $0.90(0.26-3.13)$ & $2.71(0.82-8.92)$ & $0.35(0.05-2.68)$ & $2.13(0.59-7.71)$ \\
\hline \multicolumn{5}{|l|}{ 2-1. Infant Sex } \\
\hline Boy & Reference & Reference & Reference & Reference \\
\hline Girl & $1.06(0.71-1.59)$ & $0.89(0.44-1.84)$ & $1.09(0.72-1.65)$ & $0.83(0.39-1.77)$ \\
\hline \multicolumn{5}{|l|}{ 2-2. Birth weight } \\
\hline$\geq 2500 \mathrm{~g}$ & Reference & Reference & Reference & Reference \\
\hline$<2500 \mathrm{~g}$ & $1.06(0.49-2.32)$ & $1.96(0.70-5.51)$ & $0.99(0.44-2.27)$ & $1.95(0.67-5.68)$ \\
\hline \multicolumn{5}{|l|}{ 3-1. Postpartum depression } \\
\hline No & & & Reference & Reference \\
\hline Yes & & & $1.07(0.43-2.65)$ & $7.85(3.44-17.90)^{* * *}$ \\
\hline \multicolumn{5}{|l|}{ 4-2. Feeding style } \\
\hline Only Breast feeding & Reference & Reference & Reference & Reference \\
\hline Only Bottle feeding & $1.34(0.76-2.37)$ & $1.13(0.39-3.28)$ & $1.21(0.67-2.20)$ & $0.98(0.33-2.95)$ \\
\hline Breast and bottle feeding & $1.18(0.72-1.94)$ & $2.14(0.97-4.71)$ & $1.09(0.65-1.82)$ & $1.72(0.75-3.94)$ \\
\hline
\end{tabular}

1) The multivariate analysis comprises variables that were shown to be significantly associated with impaired maternal bonding in the univariable analysis $* * * 0.0001,{ }^{* *}<0.001,{ }^{*}<0.05,+<0.10$ 
0.05 for the multivariate analysis. All the statistical analyses were carried out in SPSS 23.0.

\section{Results}

As shown in Table 2, in the bivariate analysis a number of factors during the antenatal and postnatal periods were associated with a high level of impaired maternal bonding. These were: maternal depression $(\mathrm{OR}=14.46$, $95 \% \mathrm{CI}=6.93-30.14)$, maternal stress symptoms $(\mathrm{OR}=$ $4.68,95 \% \mathrm{CI}=1.83-11.95)$, perceived maternal mental illness before pregnancy $(\mathrm{OR}=4.63,95 \% \mathrm{CI}=1.68$ 12.76), maternal negative feelings towards pregnancy $(\mathrm{OR}=2.51,95 \%$ CI $1.25-5.05)$, being primipara $(\mathrm{OR}=$ $2.49,95 \% \mathrm{CI}=1.23-5.03)$, combined breast- and bottlefeeding style $(\mathrm{OR}=2.43,95 \% \mathrm{CI}=1.15-5.15)$, and low birth-weight of the infant $(\mathrm{OR}=2.36,95 \% \mathrm{CI}=0.88$ 6.31). Moderate impairment was associated with being primipara $(\mathrm{OR}=1.78,95 \% \mathrm{CI}=1.20-2.65)$ and maternal negative feelings towards pregnancy $(\mathrm{OR}=1.45,95 \% \mathrm{CI}$ $=0.95-2.21$ ).

In multivariate analysis including depression (Table 3), maternal depression $(\mathrm{OR}=7.85,95 \% \mathrm{CI}=3.44-17.90)$ and maternal negative feelings towards pregnancy were associated with high level of impaired maternal bonding $(\mathrm{OR}=2.16,95 \% \mathrm{CI}=1.02-4.56)$. Primipara was associated with moderate level of impaired maternal bonding $(\mathrm{OR}=1.85,95 \% \mathrm{CI}=1.22-2.81)$.

We also conducted the multiple regression analyses with impaired maternal bonding as a continuous measure and confirmed that the same variables as in the logistic regression analysis, i.e. postpartum depression at 1 month after delivery $(\beta=-4.59, p<0.01)$, maternal negative feelings towards pregnancy $(\beta=-1.58, p<$ $0.01)$, and primipara $(\beta=-2.52, p<0.01)$ were significantly associated with impaired maternal bonding.

\section{Discussion}

The primary aim of this study was to examine the risk factors associated with impaired maternal bonding using a large population-based sample in Japan. A number of important findings were identified. First, there was a strong association between postpartum depression 1 month after delivery and a high level of impaired maternal bonding 3 months after delivery. Second, maternal negative feelings towards pregnancy were associated with a high level of impaired maternal bonding, and becoming a mother for the first time was associated with a moderate level of impaired maternal bonding.

The finding that depressive symptoms during the postpartum period were associated with impaired maternal bonding at 3 months after delivery is in line with a previous Swedish population-based study that reported an association between postpartum depression 6 weeks after delivery and impaired maternal bonding 6 months after delivery [14]. Previous studies have also reported that impaired maternal bonding during the antenatal and postpartum periods was associated with postpartum depression [16, 19, 37, 38]. Previous longitudinal, population-based studies in non-western countries have not included psychosocial factors such as maternal stress symptoms, the history of mental illness and feeding style, when looking at the association between impaired maternal bonding and depression [13, 18, 19, 21, 26]. The present study added new knowledge by highlighting that depressive symptoms 1 month after delivery could have an effect on impaired maternal bonding later, even after controlled for these psychosocial factors.

The association between postpartum depression and impaired maternal bonding can be explained by several mechanisms, such as depressed mothers exhibited more negative feelings including irritation and decreased interest or joy in most activities [39]. Another explanation could be that depressed mothers display cognitive bias, such as negative perceptions of themselves and others, including their infant [40] and the future [41]. The features displayed by depressed mothers might promote negative maternal feelings, such as lack of concern or hostility towards the infant-features that have also been observed in mothers with impaired maternal bonding [42]. Our findings emphasize the importance of detecting maternal depression as soon as possible after delivery.

Maternal negative feelings towards pregnancy were independently associated with the high levels of impaired maternal bonding at 3 months after delivery, despite controlling for maternal depression. Previous studies have investigated the association between maternal feelings towards pregnancy or unintended pregnancy and impaired maternal bonding at one to 2 months after delivery [15, 18]. Our finding showed that maternal negative feelings towards pregnancy in first trimester of pregnancy could effect on maternal bonding 3 months after delivery. One possible explanation of the association between maternal negative feelings towards pregnancy and impaired maternal bonding could be that mothers who had negative feelings towards pregnancy might have also unwelcoming or ambivalent feelings towards their foetus. Another plausible explanation is that mothers with unintended pregnancies were more likely to have less support from their husband or partner [27]. Our finding suggests that health-service providers should pay close attention to mothers who express negative feelings after learning of their pregnancy, and should begin providing appropriate support from the early stages of pregnancy in order to prevent impaired maternal bonding.

Having first child was associated with only moderate level of impaired maternal bonding in the final model. 
One previous study reported that first-time mothers showed higher scores of impaired maternal bonding than mothers who already had other children [24]. The transition to motherhood can be a stressful event, characterized by emotional and physical changes as well as new responsibilities and demands [43]. Furthermore, mothers may be more anxious about taking care of their first-born child. Our finding suggests that early parenting advice would make capacity to form maternal bonding for first-time mothers.

In the bivariate analysis, mothers who experienced stress symptoms, had a history of mental illness, a low birth-weight infant, and who used combined breast- and bottle-feeding, had higher odds for impaired maternal bonding when their child was 3 months old. When these associations were controlled for the effect of other explanatory variables, they did not remain significant. However, these findings indicate that several other indicators for maternal wellbeing during pregnancy may be associated with impaired maternal bonding at a later stage. Moreover, there is a possibility that these antenatal risk factors might be associated with the mother's mentalization, which is defined as the ability for one to understand their own mental state and those of others [44]. Mentalization plays an important role in the formation of the attachment between a mother and her infant [44], and it might also affect the mother's emotions towards her foetus. The association between impaired maternal bonding and the mother's mentalization ability deserves further research.

There were several limitations in this study that need to be considered. First, the participants were recruited from one Japanese city and $3.58 \%$ of the mothers were not included in the analysis because they did not want to reveal their bonding status or we did not have any information until their infants' check-ups happened 3 months after delivery. It is possible that these mothers faced increased risks of impaired maternal bonding because they had not received services from the pregnancy period to after delivery from mother and child healthcare centres in the city. It is also possible that mothers did not want to answer, because they had impaired bonding with the infant. Second, due to the limited sample size, we could not investigate the association between impaired maternal bonding and unexpected problems, such as having a baby with a very low birth-weight or pregnancy complications. Third, information about impaired maternal bonding and postpartum depression were assessed using a self-rating scale and not by clinical interviews. However, the EPDS cut-off point has been shown to correlate with postpartum depression diagnoses using structured interviews [34]. Fourth, we used only 15 items of PBQ, while Japanese version of $\mathrm{PBQ}$ was validated with 16 items later.
Fifth, it was not possible to adjust for residual confounding due to factors such as socioeconomic status, marital relationship, or infant's temperament in this study. Finally, impaired maternal bonding was only assessed 3 months after delivery, so this study could not reveal any causal association between maternal depression and impaired maternal bonding. Having information maternal bonding at the mothers' one-month follow-up visit could have strengthened the study.

The main strength of this study was the use of large, population-based sampling to investigate the risk factors of impaired maternal bonding. Of note, $91.14 \%$ of mothers 3 months after delivery living this city participated this study. This study adds to the current body of literature showing that postpartum depression can be one of the most important risk factors of impaired maternal bonding in both Japanese and Western societies. Second, the study design was longitudinal and included information collected during the first trimester of pregnancy. Thus, we found a number of antenatal factors, especially maternal negative feelings towards pregnancy, that were associated with impaired maternal bonding at 3 months after delivery.

\section{Conclusion}

Our study reported that postpartum depression and maternal negative feelings towards pregnancy were independently associated with impaired maternal bonding. These findings have important clinical implications. Depressed mothers should be identified as soon as possible after delivery, in order to prevent impaired maternal bonding, and should be assessed to check how well they are bonding with their child. Furthermore, mothers who have negative feelings towards pregnancy should be followed carefully, as this could be an early sign of an increased risk of impaired maternal bonding, regardless of the maternal postpartum depressive symptoms that may surface later.

\section{Abbreviations \\ EPDS: Edinburgh Postnatal Depression Scale; PBQ: Postpartum Bonding Questionnaire}

\section{Acknowledgements}

We wish to acknowledge the staff at Hekinan City Public Health Center for their support. We also wish to acknowledge Professor Ishii Hidetoki and Dr. Terao Takahiro for statistical advice.

\section{Funding}

This research received no specific grant from any funding agency.

\section{Availability of data and materials}

The datasets used during the current study are available from the corresponding author on reasonable request.

\section{Authors' contributions}

MN performed all statistical analysis and wrote the first draft of the manuscript. HK supervised in designing and revised the paper critically. SU, $R C, N S, T L, A S$, critically read and revised the manuscript. All authors 
participated in planning the statistical analyses and read and approved the final manuscript.

\section{Ethics approval and consent to participate}

All procedures performed in this study have been approved by the ethical committee at the Graduate School of Education and Human Development, Nagoya University, Japan (Reference number: 490). Information on participation in the study was written in the questionnaire. A verbal informed consent was obtained from all participants before including them in the study.

\section{Consent for publication}

Not applicable.

\section{Competing interests}

The authors declare that they have no competing interests.

\section{Publisher's Note}

Springer Nature remains neutral with regard to jurisdictional claims in published maps and institutional affiliations.

\section{Author details}

${ }^{1}$ Graduate School of Education and Human Development, Nagoya University, Furo-cho, Chikusa-ku, Nagoya, Japan. ${ }^{2}$ Research Center for Child Psychiatry, University of Turku, Lemminkäisenkatu 3/Teutori 3rd Floor, 20014 Turku, Finland. ${ }^{3}$ Centre for Child and Adolescent Mental Health and Child Protection, Faculty of Medicine, NTNU, NO-7491, Trondheim, Norway. ${ }^{4}$ Psychological Support and Research Center for Human Development, Nagoya University, Furo-cho, Chikusa-ku, Nagoya, Japan.

Received: 22 February 2018 Accepted: 27 February 2019

Published online: 08 March 2019

\section{References}

1. Klaus MH, Kennell JH. Maternal-infant bonding: the impact of early separation or loss on family development. Saint Louis: Mosby; 1976

2. Condon JT. The assessment of antenatal emotional attachment: development of a questionnaire instrument. Br J Med Psychol. 1993;66(2): 167-83.

3. Rossen L, Hutchinson D, Wilson J, Burns L, Olsson CA, Allsop S, Elliott EJ, Jacobs S, Macdonald JA, Mattick RP. Predictors of postnatal mother-infant bonding: the role of antenatal bonding, maternal substance use and mental health. Arch Womens Ment Health. 2016:19(4):609-22.

4. Muller ME. Prenatal and postnatal attachment: a modest correlation. J Obstet Gynecol Neonatal Nurs. 1996;25(2):161-6.

5. Kitamura T, Ohashi Y, Kita S, Haruna M, Kubo R. Depressive mood, bonding failure, and abusive parenting among mothers with three-month-old babies in a Japanese community. Open J Psychiatry. 2013;3(03):1-7.

6. Noorlander $Y$, Bergink V, Van den Berg MP. Perceived and observed mother-child interaction at time of hospitalization and release in postpartum depression and psychosis. Arch Womens Ment Health. 2008; 11(1):49-56.

7. Hairston IS, Waxler E, Seng JS, Fezzey AG, Rosenblum KL, Muzik M. The role of infant sleep in intergenerational transmission of trauma. Sleep. 2011: 34(10):1373-U1115.

8. Chandra PS, Desai G, Reddy D, Thippeswamy H, Saraf G. The establishment of a mother-baby inpatient psychiatry unit in India: adaptation of a Western model to meet local cultural and resource needs. Indian J Psychiatry. 2015; 57(3):290.

9. Garcia-Esteve L, Torres A, Lasheras G, Palacios-Hernandez B, Farre-Sender B, Subira S, Valdes M, Brockington IF. Assessment of psychometric properties of the postpartum bonding questionnaire (PBO) in Spanish mothers. Arch Womens Ment Health. 2016:19(2):385-94.

10. Loh CC, Vostanis P. Perceived mother-infant relationship difficulties in postnatal depression. Infant Child Dev. 2004;13(2):159-71.

11. Parfitt YM, Ayers S. The effect of post-natal symptoms of post-traumatic stress and depression on the couple's relationship and parent-baby bond. J Reprod Infant Psychol. 2009;27(2):127-42.

12. Siu BW-M, Ip P, Chow HM-T, Kwok SS-P, Li O-L, Koo M-L, Cheung EF-C, Yeung TM-H, Hung S-F. Impairment of mother-infant relationship: validation of the Chinese version of postpartum bonding questionnaire. J Nerv Ment Dis. 2010;198(3):174-9.

13. Edhborg M, Nasreen HE, Kabir ZN. Impact of postpartum depressive and anxiety symptoms on mothers' emotional tie to their infants 2-3 months postpartum: a population-based study from rural Bangladesh. Arch Womens Ment Health. 2011;14(4):307-16.

14. Kerstis B, Aarts C, Tillman C, Persson H, Engstrom G, Edlund B, Ohrvik J, Sylven S, Skalkidou A. Association between parental depressive symptoms and impaired bonding with the infant. Arch Womens Ment Health. 2016; 19(1):87-94.

15. Perry DF, Ettinger AK, Mendelson T, Le HN. Prenatal depression predicts postpartum maternal attachment in low-income Latina mothers with infants. Infant Behav Dev. 2011:34(2):339-50.

16. Dubber S, Reck C, Muller M, Gawlik S. Postpartum bonding: the role of perinatal depression, anxiety and maternal-fetal bonding during pregnancy. Arch Womens Ment Health. 2015;18(2):187-95.

17. Moehler E, Brunner R, Wiebel A, Reck C, Resch F. Maternal depressive symptoms in the postnatal period are associated with long-term impairment of mother-child bonding. Arch Womens Ment Health. 2006;9(5):273-8.

18. Kokubu M, Okano T, Sugiyama T. Postnatal depression, maternal bonding failure, and negative attitudes towards pregnancy: a longitudinal study of pregnant women in Japan. Arch Womens Ment Health. 2012;15(3):211-6.

19. Nagata M, Nagai $Y$, Sobajima H, Ando T, Honjo S. Depression in the mother and maternal attachment - results from a follow-up study at 1 year postpartum. Psychopathology. 2003;36(3):142-51.

20. Ohara M, Okada T, Kubota C, Nakamura Y, Shiino T, Aleksic B, Morikawa M, Yamauchi A, Uno Y, Murase S, et al. Validation and factor analysis of mother-infant bonding questionnaire in pregnant and postpartum women in Japan. BMC Psychiatry. 2016;16:7.

21. Ohoka H, Koide T, Goto S, Murase S, Kanai A, Masuda T, Aleksic B, Ishikawa $\mathrm{N}$, Furumura K, Ozaki N. Effects of maternal depressive symptomatology during pregnancy and the postpartum period on infant-mother attachment. Psychiatry Clin Neurosci. 2014;68(8):631-9.

22. Yoshida K, Yamashita H, Conroy S, Marks M, Kumar C. A Japanese version of mother-to-infant bonding scale: factor structure, longitudinal changes and links with maternal mood during the early postnatal period in Japanese mothers. Arch Womens Ment Health. 2012;15(5):343-52.

23. Nonnenmacher N, Noe D, Ehrenthal J, Reck C. Postpartum bonding: the impact of maternal depression and adult attachment style. Arch Womens Ment Health. 2016:19(5):927-35.

24. Suetsugu Y, Honjo S, Ikeda M, Kamibeppu K. The Japanese version of the postpartum bonding questionnaire: examination of the reliability, validity, and scale structure. J Psychosom Res. 2015;79(1):55-61.

25. Cinar N, Kose D, Altinkaynak S. The relationship between maternal attachment, perceived social support and breast-feeding sufficiency. J Coll Physicians Surg Pak. 2015;25(4):271-5

26. Kita S, Haruna M, Matsuzaki M, Kamibeppu K. Associations between intimate partner violence (IPV) during pregnancy, mother-to-infant bonding failure, and postnatal depressive symptoms. Arch Womens Ment Health. 2016;19(4):623-34

27. Goto A, Yasumura S, Yabe J, Reich MR. Addressing Japan's fertility decline: influences of unintended pregnancy on child rearing. Reprod Health Matters. 2006;14(27):191-200

28. van Reenen $S L$, van Rensburg E. The influence of an unplanned caesarean section on initial mother-infant bonding: mothers' subjective experiences. J Psychol Afr. 2013:23(2):269-74.

29. Feldman R, Weller A, Leckman JF, Kuint J, Eidelman Al. The nature of the mother's tie to her infant: maternal bonding under conditions of proximity, separation, and potential loss. J Child Psychol Psychiatry. 1999;40(6):929-39.

30. Robson KS, Moss HA. Patterns and determinants of maternal attachment. J Pediatr. 1970;77(6):976-85.

31. Brockington IF, Oates J, George S, Turner D, Vostanis P, Sullivan M, Loh C, Murdoch C. A screening questionnaire for mother-infant bonding disorders. Arch Womens Ment Health. 2001;3(4):133-40.

32. Kaneko H, Honjo S. The psychometric properties and factor structure of the postpartum bonding questionnaire in Japanese mothers. Psychology. 2014; 5(09):1135.

33. Cox JL, Holden JM, Sagovsky R. Detection of postnatal depression. Development of the 10-item Edinburgh postnatal depression scale. Br J Psychiatry. 1987;150:782-6.

34. Okano T. Validation and reliability of a Japanese version of the EPDS. Arch Psychiatr Diagn Clin Eval. 1996;7:525-33. 
35. Yamashita H, Yoshida K, Nakano H, Tashiro N. Postnatal depression in Japanese women. Detecting the early onset of postnatal depression by closely monitoring the postpartum mood. J Affect Disord. 2000;58(2):145-54.

36. Zieky MJ. So much has changed- an historical overview of setting cut scores. In: Cizek GJ, editor. Setting performance standards foundations, methods, and innovations. New York: Routledge; 2011. p. 15-32.

37. Goecke T, Voigt F, Faschingbauer F, Spangler G, Beckmann M, Beetz A. The association of prenatal attachment and perinatal factors with pre-and postpartum depression in first-time mothers. Arch Gynecol Obstet. 2012 286(2):309-16.

38. Ohara M, Okada T, Kubota C, Nakamura Y, Shiino T, Aleksic B, Morikawa M, Yamauchi A, Uno Y, Murase S. Relationship between maternal depression and bonding failure: a prospective cohort study of pregnant women. Psychiatry Clin Neurosci. 2017;71(10):733-41.

39. Patel M, Bailey RK, Jabeen S, Ali S, Barker NC, Osiezagha K. Postpartum depression: A Review. J Health Care Poor Underserved. 2012;23(2):534-42.

40. Stein A, Arteche A, Lehtonen A, Craske M, Harvey A, Counsell N, Murray L. Interpretation of infant facial expression in the context of maternal postnatal depression. Infant Behav Dev. 2010;33(3):273-8.

41. Beck AT. Cognitive therapy of depression. New York: Guilford press; 1979.

42. Kumar RC. "Anybody's child": severe disorders of mother-to-infant bonding. Br J Psychiatry. 1997:171:175-81.

43. Razurel C, Bruchon-Schweitzer M, Dupanloup A, Irion O, Epiney M. Stressful events, social support and coping strategies of primiparous women during the postpartum period: a qualitative study. Midwifery. 2011;27(2):237-42.

44. Fonagy $\mathrm{P}$, Gergely $\mathrm{G}$, Jurist EL. Affect regulation, mentalization and the development of the self. London: Karnac books; 2004.

Ready to submit your research? Choose BMC and benefit from:

- fast, convenient online submission

- thorough peer review by experienced researchers in your field

- rapid publication on acceptance

- support for research data, including large and complex data types

- gold Open Access which fosters wider collaboration and increased citations

- maximum visibility for your research: over $100 \mathrm{M}$ website views per year

At BMC, research is always in progress.

Learn more biomedcentral.com/submissions 